\title{
Research on the Talent Demand of Industrial Clusters and the Transformation of Newly Established Undergraduate Colleges
}

\author{
Tao Li \\ Baicheng Normal University, Baicheng, Jilin, 137000, China \\ email: 2975777902@qq.com
}

\begin{abstract}
Keywords: Talent demand; Newly established undergraduate colleges; Industrial clusters; Professional characteristics; Professional transformation
\end{abstract}

\begin{abstract}
In order to adapt to the actual needs of the economic structure better and give full play to the advantages of colleges and universities to cultivate all kinds of talents, the new undergraduate colleges need to focus on the adjustment of professional structure and accelerate the pace of professional transformation. When expanding their own school scale in the industrial cluster areas, Colleges and universities need to fully consider the talent needs of industrial clusters combined with the actual situation of the region, and gradually form a unique professional layout to ensure the sustainable development of colleges and universities. At the same time, in order to adapt to the development trend of education popularization and localization better, new undergraduate colleges should improve the correct understanding of the necessity of professional transformation, strengthen professional connotation construction, and analyze talent demand characteristics of industrial clusters in-depth, for ensuring a good local economic development. New undergraduate colleges should fully consider the professional construction planning rationality in setting different majors, and constantly improve the professional connotation, highlight the professional characteristics, take reasonable measures to intensify the adjustment of professional structure, making the new undergraduate colleges have a competitive advantage in the future development.
\end{abstract}

\section{Introduction}

According to the actual situation of the current economic and social development, we can find the relation between higher education and economic social structure more closely, universities need to fully consider the actual needs of regional economic development, maintain the professional structure rationality, and enhance the self running practice level. At the same time, because the industrial structure has a certain effect on the professional structure, we need to pay attention to the analysis on the characteristics of talent demand of industrial clusters, and provide reliable guarantee for the realization of the target of scientific and reasonable professional structure. In this situation, the newly-built universities and colleges should fully consider the actual needs of different professionals in various industries in the professional setting, pay attention to the professional transformation, maintain their own good level of competition while promoting the rapid development of the regional economy, and lay a solid foundation for the gradual expansion of the scale of the development of higher education in China.

\section{An Overview of the Industrial Clusters and the Professional Transformation of Newly Established Undergraduate Colleges}

Overview of Industrial Clusters. The concept of the industry was first put forward by the American scholar Mike Porter, which refers to the group formed by the enterprises and corporate body that have the interactive relationship in the specific domain. Industrial clusters are closely related with regional economy, in the influence of industrial clusters, economy cluster can provide the necessary impetus to the stability development of China's economic society, and effectively solve various social problems, such as unemployment, rural issues, expansion of the industrial scale, industrial upgrading [1]. Attention to the development of industrial clusters can promote the rapid development of regional economy, and provide reliable guarantee for the sustained growth of 
economic benefits in different regions of our country. At present, the "emerging areas" of developed countries, such as the United States, "Silicon Valley", all belong to the model of industrial clusters, which maintain a good level of international competition and promote the development of regional economy.

Overview of the Professional Transformation of Newly Established Undergraduate Colleges. With the expansion of influence scope of the higher education popularization, the number of newly established undergraduate colleges in our country is gradually increasing. These newly established undergraduate colleges and universities are influenced by the needs of different levels of talent and diverse tasks of the various sectors of the society in the professional settings, which has brought great challenges to the determination of the orientation of their school and the direction of development [2]. At the same time, because the reasonable setting of disciplines and majorsit has a great impact on the long-term development of newly established universities, therefore, they need to pay attention to set up professional science in discipline construction, strengthen professional construction, and enhance their overall educational level. The so-called professional transformation refers to making the necessary changes in the professional structure, form, content and other aspects to achieve the establishment of a comprehensive university. The professional structure adjustment of new undergraduate colleges not only adapt to the requirements of the talent market demand and the strategic adjustment of the economic structure, but also provides an important guarantee for the professional level of technical expertise and application subject, which is very important for the establishment of the strategic plan and the realization of the strategic objectives.

\section{Analysis on the Demand Characteristics of Industrial Clusters}

Analysis on the Characteristics of Industrial Clusters' demand Level. Combined with the actual situation of the current industrial cluster talent demand, the hierarchical characteristics is clear. The hierarchical characteristics of the industrial cluster's talent demand are the promotion from the general human capital to the professional human capital in essence [3]. Whereby, human capital includes general human capital, professional human capital and entrepreneur human capital. At the present stage, there is an imbalance in the proportion of talent structure in the industrial clusters, especially in the high level, high degree of talent allocation ratio. The personnel structure imbalance affects the sustainable development of enterprises, so that the technical level of enterprises in the long time development process can not be really improved, their own R \& D capability can not meet the actual needs of stable development of enterprises. The lack of talent in industrial clusters specifically performs: the shortage of technical talent, innovative talent is obvious; on the other hand, high-quality talents are lack, talent education background needs to be improved, the proportion of bachelor degree or above and skilled workers is low, that is difficult to achieve the actual needs of large-scale enterprise skilled operation technology. Therefore, we need to focus on the analyze the talents demand characteristics of industrial clusters, and realize the talents demand industry cluster upgrade from general human capital to professional human capital, which reflects the necessity of professional transition of new undergraduate institutions in a certain extent.

Analysis on Industry Characteristics of Talent Demand in Industrial Clusters. In order to meet the needs of all kinds of talents, we need to pay attention to analysis on industry characteristics of talent demand in industrial clusters. Through the effective analysis of the industry talent demand in industrial clusters, it can be seen that the talent of manufacturing industry is the most scarce, the main reason is that there are a large number of manufacturing clusters, and there is a large demand for technical talents in product production and processing. However, on the basis of a comprehensive assessment of the ability cultivation of talents in Colleges and universities, it is difficult to meet the industry demand for talent, it is necessary for further expansion of scale of construction of new undergraduate colleges, under the premise to ensure the rationality of setting up the professional, comprehensively improve the level of personnel training in Colleges and universities, fully meet the actual needs of manufacturing personnel, to ensure the steady development of the manufacturing industry. At the same time, through the analysis and summary of the reasons for the ability of talents training in Colleges and universities to meet the needs of the 
manufacturing industry, it is found that the reasons include these aspects: the overall distribution of talent structure is unreasonable, the high-level personnel lack; highly educated personnel is lack of, skilled personnel less. Therefore, in order to speed up the development speed of industrial clusters industrialization, adapt to the development demand of the era of knowledge economy, we need to set up a reasonable training system of university personnel structure, increase efforts to train personnel to meet the various industrial clusters.

Analysis on Regional Characteristics of Talent Demand in Industrial Clusters. Focusing on the effective analysis of the industrial cluster's talent demand, it is necessary to pay attention to the analysis of the regional characteristics of the talent demand combining with the actual development of the industrial clusters [4-6]. When industrial clusters are highly concentrated, the demand for talent in these areas will be concentrated. From the view of the main distribution areas of our country, we can find that there are many industrial clusters in the eastern coastal areas, and the overall level of economic development is higher than other regions. In the industrial clusters, the demand of the regional private SMEs is relatively large. Therefore, the regional demand for private SMEs should be taken into account in the analysis of the regional characteristics of industrial clusters. In the analysis of the spatial distribution of industrial clusters in different regions, it is found that the spatial distribution of these clusters is not balanced, and the demand for private enterprises in economically developed areas is more obvious. However, due to the lack of professional talents, the problem of brain drain is too serious, to a certain extent, that restricts the expansion of the scale of the small and medium-sized private enterprises.

Analysis on Professional Characteristics of Talent Demand in Industrial Clusters. At present, there are a large number of labor-intensive enterprises in the industrial clusters in China, their main advantages are: low cost, low technology content, and obtaining economic benefits by imitating various products [7]. With the expansion of the impact scope of economic globalization, for these phenomenon in industrial clusters governments gradually increased the intensity of macroeconomic regulation and control, resulting in labor-intensive production costs to increase gradually, which objectively determines the necessity of structure adjustment of traditional industrial cluster enterprise. According to the analysis of talent demand of the professional structure in the industrial clusters, we can see that it has the characteristics of these areas: technology, design, marketing and front-line technicians are very scarce. With the intensification of the economic growth mode of the industrial cluster, the demand of the related personnel is diversified, which requires the university to pay attention to the effective training of the advanced talents.

\section{Analysis on the Main Points of Professional Transformation of Newly Established Undergraduate Colleges}

In order to better meet the needs of the industrial clusters, and highlight the competitive advantage of the future development of the newly established undergraduate colleges, it is necessary to strengthen the professional construction, and realize the scientific transformation under the support of specific planning programs. To achieve this goal, we need to start from the following aspects::

Clear the Prerequisite for Professional Transformation, Focus on Professional Development Planning. In order to achieve the professional transformation of the newly established undergraduate colleges, we need to make clear the prerequisites for professional transformation, and enhance the rationality of professional construction planning, which is manifested in: strengthening the rational use of professional guiding ideology, in-depth understanding of the connotation of Scientific Outlook on Development, making the social demand for professional disciplines as a new undergraduate colleges professional transition points, cultivating a solid foundation, innovation ability, practice ability outstanding application talents for the society; strictly abiding by the application, forward-looking, innovative, cost-effective principle of professional construction, clearing professional transformation thinking; according the requirements of professional construction and professional transformation, adopting security measures of strengthening leadership of the professional construction, establishment of discipline management system, perfecting the guarantee mechanism of funds, improving the mechanism of professional acceptance 
and other measures, to ensure good professional construction and promote the realization of the goal of professional transformation.

Clear the Key to Professional Transformation, Reasonably Adjust Professional Structure. Based on the in-depth analysis of the professional construction and professional transformation of the newly established undergraduate colleges, it is found that the key to the transformation is to adjust the professional structure reasonably, which is manifested in: combined with the needs of industrial clusters, enhancing the rationality of professional settings, and maintaining the good dynamic adjustment of the professional structure; strengthening the local leading industry and the overall development situation analysis to ensure cohesion and the tightness of the professional development with these leading industries, increasing the number of non normal professional application, and finally making the new undergraduate colleges to form professional group with characteristics, promoting and adapting to the local pillar industry development in industry. At the same time, needing to pay attention to the construction of specialty connotation and other long-term, enriching the connotation of professional; deepening the reform of the traditional disciplines, enhancing the actual effect of these professional reform, optimizing the resources allocation and strengthening the connection between different disciplines, achieving the new undergraduate colleges and universities across the faculties of professional, a variety of teaching resources sharing.

Clear the Emphasis of Professional Transformation, Enhance the Professional Connotation Comprehensively. In order to realize the goal of the transformation of the newly established undergraduate colleges, we should pay attention to the optimization of the professional structure, strengthen the optimization of the professional structure and structure, and ensure the reliability of the quality of personnel training. The current professional transformation of newly established colleges and universities focus on the promotion of professional connotation, which is manifested in: adhering to scientific development, focusing on the analysis of the situation of market economy, maintaining stability development of undergraduate education and optimizing the structure of professional colleges, making the professional setting to meet the practical needs of all sectors of society, promote professional content meet the needs of professional transformation; clearing undergraduate talents training goal, solid professional knowledge, improving their comprehensive ability to use professional knowledge to solve practical problems, training applied talents and reliable application talents, perfecting teaching content system, realizing the professional transformation of colleges; building a high level of professional teaching staff, and constantly strengthening the construction of professional practice teaching, establishing a reliable professional practice base to ensure the quality of professional talents of the new undergraduate colleges and universities.

Clear Direction of Professional Transformation, Enhance the Cultivation Effect of Professional Characteristics. The prominent characteristics of the newly established undergraduate colleges and universities have an important practical significance for their professional transformation. At this stage, the orientation of the transformation of newly established undergraduate colleges and universities is the scientific cultivation of professional characteristics, which is manifested in: determining the specialty cultivation target, combined with the orientation of the colleges and universities, regional industrial cluster characteristics, to develop reliable specialty cultivation measures, improving the relevant personnel training plan, to ensure the smooth realization of specialty cultivation goal; through the cultivation of talents training mode, the interaction between school and enterprise, and the cultivation of professional characteristics such as subject support, highlighting the professional characteristics of the new undergraduate colleges and universities; paying attention to the effective use of information technology and computer networks, to provide protection for the cultivation of professional characteristics.

\section{Conclusion}

To sum up, It is conducive to promoting the steady development of the regional economy, realize the goal of development of a harmonious society in China, to expand the scope of the actual impact of higher education that strengthening the analysis of industry cluster talent demand characteristics, 
in-depth understanding of the actual situation,. adjusting industrial structure, accelerating the transformation of new undergraduate colleges professional speed. Therefore, in order to better adapt to the market economic system reform and industrial cluster development trend, promote the popularization of higher education in China, it is necessary to give full play to the advantages of new undergraduate colleges, and promote their professional transformation, realize the transformation of the traditional professional construction mode, to better meet the diversity of flower industry cluster district talent demand. In the future development of new undergraduate colleges should be combined with the demand of industrial clusters, their strategic development should improve the understanding of the professional transformation and implementation, to complete the transformation of professional construction mission and highlight the school characteristics, realize the social influence, the educational goals of comprehensive university professional special good. In the future development, new undergraduate colleges should be combined with the demand of industrial cluster and its strategic deployment, improve the understanding of the professional transformation, complete the mission of professional construction transformation and highlight the school characteristics, to realize comprehensive university educational goals of great social influence, good professional characteristics.

\section{References}

[1]Kong Su. Research on the training mode of applied talents under background of the transformation and development of local undergraduate colleges and Universities[D]. Guangxi Normal University,2015(06).

[2]Zeng Ling. Research on the transformation and development of newly established Universities[D]. Guangxi Normal University,2015(05).

[3]Sheng Xin. A study on the quality and guarantee mechanism of talents training in newly built local universities[D]. Hunan Normal University,2015(06).

[4]Xie Lingling. The construction, operation and evaluation of ecological niche strategy in newly built universities[D]. Nanjing agricultural university, 2011(12).

[5]Kong Dong. Research on the construction of characteristic specialty in newly built Universities[D]. Nanjing normal university, 2013(03).

[6]Qian Li, Yuan Boqiao. Research on the construction mode of the professional cluster in the transformation and development of newly established local universities[J]. Journal of Chongqing university of education,2015(01).

[7]Guo Mengdie. Research on the construction of teachers in the transformation and development of newly established local universities[D]. Henan university,2015(05).

[8]Hao Jinshi. Research on the development strategy and strategic management of newly established local universities[D]. Huazhong university of science and technology,2010(11). 